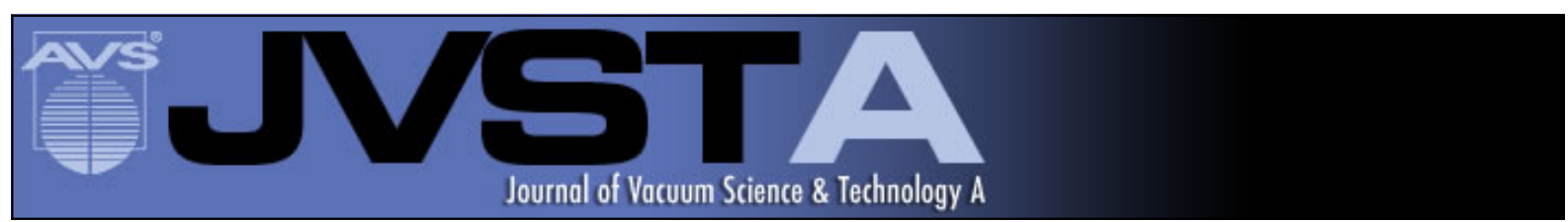

\title{
Methanol decomposition on single crystal Cu2O
}

David F. Cox and Kirk H. Schulz

Citation: Journal of Vacuum Science \& Technology A 8, 2599 (1990); doi: 10.1116/1.576678

View online: http://dx.doi.org/10.1116/1.576678

View Table of Contents: http://scitation.aip.org/content/avs/journal/jvsta/8/3?ver=pdfcov

Published by the AVS: Science \& Technology of Materials, Interfaces, and Processing

\section{Articles you may be interested in}

Cu2O by XPS

Surf. Sci. Spectra 5, 257 (1998); 10.1116/1.1247881

Stoichiometric and Non-Stoichiometric Cu2O(111) Single Crystal Surfaces

Surf. Sci. Spectra 4, 279 (1996); 10.1116/1.1247798

Birefringence and structural defects in Cu2O crystals

J. Appl. Phys. 54, 2605 (1983); 10.1063/1.332333

Abstract: Laminar Cu2O growth on (111) Cu singlecrystal surfaces

J. Vac. Sci. Technol. 15, 656 (1978); 10.1116/1.569658

Surface and Bulk Conductivities of Cu2O Single Crystals

J. Appl. Phys. 41, 271 (1970); 10.1063/1.1658333
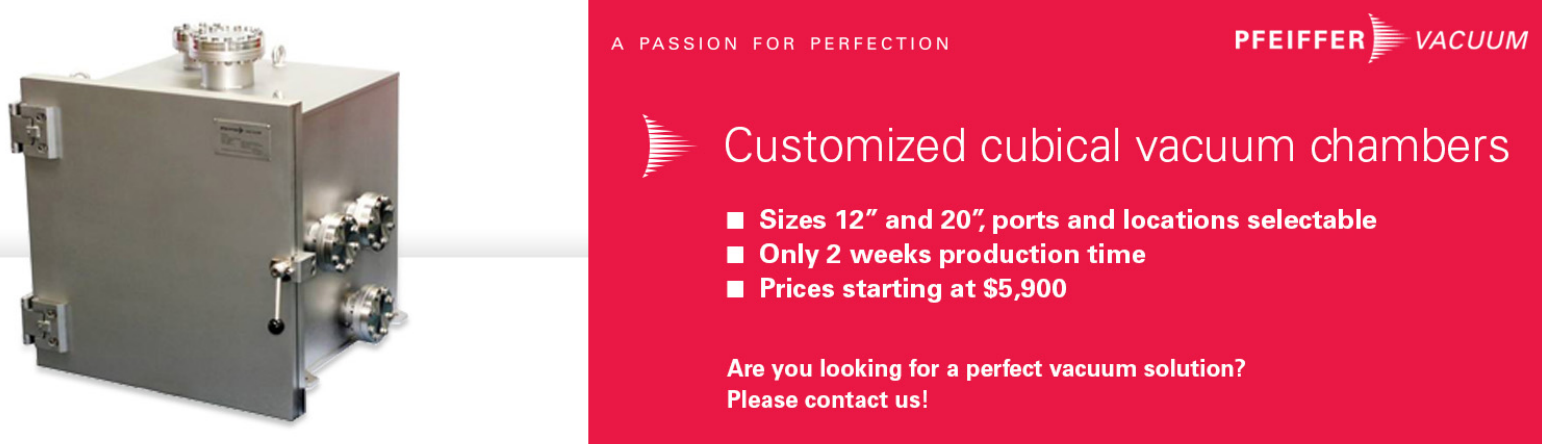
Copyright by the AIP Publishing. Cox, D. F.; Schulz, K. H., "Methanol decomposition on single-crystal cu2o," J. Vac. Sci. Technol. A 8, 2599 (1990); http://dx.doi.org/10.1116/1.576678

\title{
Methanol decomposition on single crystal $\mathrm{Cu}_{2} \mathrm{O}$
}

\author{
David F. Cox a) and KirkH. Schulz \\ Department of Chemical Engineering. Virginia Polytechnic Institute and State University, \\ Blacksburg, Virginia 24061
}

(Received 1 September 1989; accepted 30 October 1989)

\begin{abstract}
$\mathrm{CH}_{3} \mathrm{OD}$ decomposition has been studied over the stoichiometric, nonpolar (111) and polar, copper-terminated (100) surfaces of $\mathrm{Cu}_{2} \mathrm{O}$. Thermal desorption studies for monolayer coverages of methanol at $90 \mathrm{~K}$ show similar conversions, but the product distributions vary significantly, indicating a structure sensitive reaction. The (11i) surface shows a maximum selectivity for complete oxidative dehydrogenation to $\mathrm{CO}$, while the (100) surface shows a maximum selectivity for partial dehydrogenation to $\mathrm{CH}_{2} \mathrm{O}$. Thermal desorption spectroscopy (TDS) and $\mathrm{x}$-ray photoelectron spectroscopy (XPS) data are consistent with a decomposition pathway which proceeds through a methoxy intermediate for both surfaces. Possible origins for the structure sensitivity are discussed.
\end{abstract}

\section{INTROOUCTION}

The decomposition of methanol has been used often as a probe reaction for investigating the oxidation chemistry of catalytic materials in ultrahigh vacuum (UHV). While a significant number of studies have been carried out on clean and modified single crystal transition metal surfaces," very few studies are avaliable over well characterized metal oxide surfaces. The most thoroughly studied metal oxide single crystal surfaces are the polar (0001) and the nonpolar (1010) $\mathrm{ZnO}$ surfaces. ${ }^{2-5} \mathrm{ZnO}$ is notable for the structure sensitivity it displays in methanol dissociation depending on the accessibility of acid-base site pairs at the surface. ${ }^{4}$

Most studies show that methanol decomposition proceeds through a stable surface methoxy $\left(\mathrm{CH}_{3} \mathrm{O}\right.$-) intermediate. ${ }^{1-4}$ Typical reactions of surface methoxy include oxidative dehydrogenation to formaldehyde $\left(\mathrm{H}_{2} \mathrm{CO}\right)$ and $\mathrm{CO}$, recombination with hydrogen to give methanol, and oxidation to surface formate ( $\mathrm{HCOO}$-). In addition to providing information on the catalytic oxidation of methanol, such studies can provide insight into the types of surface intermediates important in the methanol synthesis reaction. Methoxy and formate intermediates have been observed in UHV studies over $\mathrm{Cu}^{6,7}$ and $\mathrm{ZnO}^{2-5}$ single crystal surfaces, and have also been detected via chemical trapping techniques over the industrial $\mathrm{Cu} / \mathrm{ZnO}$ catalyst at high pressure during the synthesis reaction. ${ }^{8-10}$

In the $\mathrm{Cu} / \mathrm{ZnO}$ system, an apparent synergism results from the combination of the two materials to yield a catalyst with superior operating characteristics (lower $T$ and $P$ ) than those of the individual components. A number of possibilities have been proposed for the active site on $\mathrm{Cu} / \mathrm{ZnO}$ catalysts. These possibilities include: (1) metallic copper clusters which exhibit no new properties as a result of mixing with $\mathrm{ZnO},{ }^{11-13}(2)$ highly defective (oxygen-deficient) $\mathrm{ZnO}$ overlayers on Cu crystallites, ${ }^{14}$ and ( 3 ) $\mathrm{Cu}{ }^{+1}$ cations stabilized by substitutional dissolution in the surface of the $\mathrm{ZnO}$ lattice., ${ }^{85-17}$ Several UHV studies have modeled the $\mathrm{Cu} / \mathrm{ZnO}$ system by depositing $\mathrm{Cu}$ on $\mathrm{ZnO}$ thin films ${ }^{18}$ or single crystal surfaces. ${ }^{19}$ These studies demonstrate that it is difficult to spectroscopically characterize the oxidation state of low coverages of $\mathrm{Cu}$ on $\mathrm{ZnO},{ }^{19}$ and that it may not be possible to isolate $\mathrm{Cu}^{+1}$ cations in the $\mathrm{ZnO}$ matrix without the simultaneous presence of metallic Cu crystallites. ${ }^{18}$

Since $\mathrm{Cu}^{+1}$ cations have been proposed as one of the possible active sites in methanol synthesis, ${ }^{8,15-17}$ we have undertaken a study of the interaction of methanol with model $\mathrm{Cu}_{2} \mathrm{O}$ surfaces which provide a high density of $\mathrm{Cu}^{+1}$ cations. While the chemistry of $\mathrm{Cu}^{+}{ }^{+}$ions imbedded in a $\mathrm{ZnO}$ matrix may differ somewhat from those in the $\mathrm{Cu}_{2} \mathrm{O}$ matrix, the use of the single component cuprous oxide allows one to investigate the chemistry of unpromoted $\mathrm{Cu}^{+1}$ in the absence of detectable amounts of Cu metal. Note that it is not possible to test $\mathrm{Cu}_{2} \mathrm{O}$ as a catalyst under industrial reaction conditions because the syngas environment $\left(\mathrm{H}_{2}\right.$ and $\left.\mathrm{CO}\right)$ is highly reducing, and pure copper oxide is converted to metallic copper. UHV surface science studies of the methanol decomposition reaction therefore provide the best means of testing the chemistry of a pure $\mathrm{Cu}^{+1}$ oxide phase. These studies provide information on the types of surface intermediates formed by $\mathrm{Cu}^{+1}$ centers not promoted by $\mathrm{ZnO}$.

\section{EXPERIMENTAL}

The $\mathrm{Cu}_{2} \mathrm{O}$ samples used in this study were grown by a float $z$ one technique using an arc-image furnace. ${ }^{20}$ The crystals were oriented by Laue backreflection and mechanically polished to within $1^{\circ}$ of the (100) and (111) surfaces. Sample dimensions were approximately $7 \times 5 \times 1 \mathrm{~mm}^{3}$. The crystals were $p$-type semiconductors, and had a bulk resistivity of about $10^{3} \Omega \mathrm{cm}$ at room temperature. Ion bombardment and annealing was used to clear and order the surfaces, and their condition was monitored by $\mathrm{X}$-ray photoelectron spectroscopy (XPS). Thermal desorption spectroscopy (TDS) and XPS experiments for $\mathrm{Cu}_{2} \mathrm{O}(111)$ were performed on a stoichiometric surface exhibiting a hexagonal $(1 \times 1)$ low-energy electron diffraction (LEED) pattern. The polar $\mathrm{Cu}_{2} \mathrm{O}(100)$ surface was a reconstructed, copper-terminated surface, and exhibited a $(3 \sqrt{2} \times \sqrt{2}) R 45^{\circ}$ LEED pattern.

All experiments were conducted in a turbopumped, dualchamber, stainless steel UHV system. Sample transport between the two chambers was accomplished via a sample rod which passed through a differentially pumped sliding seal 
separating the two chambers. XPS studies were run in the analysis chamber equipped with a Leybold EA-11 hemispherical analyzer and a dual anode $\mathrm{Mg} / \mathrm{Al}$ x-ray source. For the XPS measurements, $\mathrm{Mg} K \alpha$ radiation was used exclusively, and the analyzer was run at a resolution corresponding to a full width at half-maximum (FWHM) of 0.95 $\mathrm{eV}$ on the $\mathrm{Ag} 3 d_{5 / 2}$ peak. TDS and LEED studies were performed in the preparation chamber using an Inficon Quadrex 200 mass spectrometer and VG 3-grid reverse-view LEED optics, respectively. The base pressure of the system was $4 \times 10^{-11}$ Torr in the analysis chamber and $7 \times 10^{-13}$ Torr in the preparation chamber.

For sample handling in UHV, the samples were clamped with titanium shims to a stainless steel stage which provided mechanical stability and acted as an indirect heating and cooling source. Since the samples were fragile and thin (1 mm or less), a type $K$ thermocouple was attached to the heating stage for temperature measurements. This arrangement did not provide a direct measure of the sample temperature.

Gas exposures for the TDS experiments were performed by backfilling the chamber through a variable leak valve. The $\mathrm{CH}_{3}$ OD used in this study (Aldrich $99.5+$ atom \% D) was degassed by repeated freeze-pump-thaw cycles prior to use. The background pressure between TDS runs was $2 \times 10^{-10}$ Torr or better. All exposures were at sample temperatures of $90 \mathrm{~K}$. For TDS experiments, a $2 \mathrm{~K} / \mathrm{s}$ linear temperature ramp was applied to the sample stage, and up to six masses were monitored simultaneously. All desorption traces were corrected for the mass spectrometer sensitivity. Although the sample temperature was monitored indirectly during the TDS runs, independent measurements of the crystal temperature were used to more closely relate the recorded temperature for a TDS ramp to the crystal temperature during the ramp. Our value of $155 \mathrm{~K}$ for the desorption temperature of methanol multilayers compares reasonably with the value of $150 \mathrm{~K}$ over $\mathrm{Cu}(100) \cdot{ }^{21} \mathrm{~A}$ comparison between values for our two $\mathrm{Cu}_{2} \mathrm{O}$ crystals showed a variation of less than $5 \mathrm{~K}$.

The mass spectrometer was equipped with a quartz skimmer to minimize the sampling of desorption products from the crystal support hardware. Additionally, desorption traces were collected from the titanium shims and the back of the sample stage to ensure that their contribution to the traces collected over the crystals was negligible.

\section{RESULTS}

\section{A. Thermal desorption spectroscopy}

\section{1. $\mathrm{Cu}_{2} \mathrm{O}(111)$}

The products of the reaction of $\mathrm{CH}_{3} \mathrm{OD}$ with the $\mathrm{Cu}_{2} \mathrm{O}(111)$ surface are shown in Fig. 1. A near saturation coverage was achieved by exposing the $90 \mathrm{~K}$ surface to $2 \mathrm{~L}$ (corrected for ion gauge sensitivity) of $\mathrm{CH}_{3} \mathrm{OD}(1 \mathrm{~L} \equiv$ $1 \times 10^{-6}$ Torrs). Methanol was oxidized to $\mathrm{CO}, \mathrm{CO}_{2}$, $\mathrm{CH}_{2} \mathrm{O}$, and water. Other products checked for but not detected included $\mathrm{CH}_{4}$ for evidence of $\mathrm{CO}$ bond breaking, and $\mathrm{CH}_{3} \mathrm{OCH}_{3}$ and $\mathrm{HCOOCH}_{3}$ as products of bimolecular surface reactions.

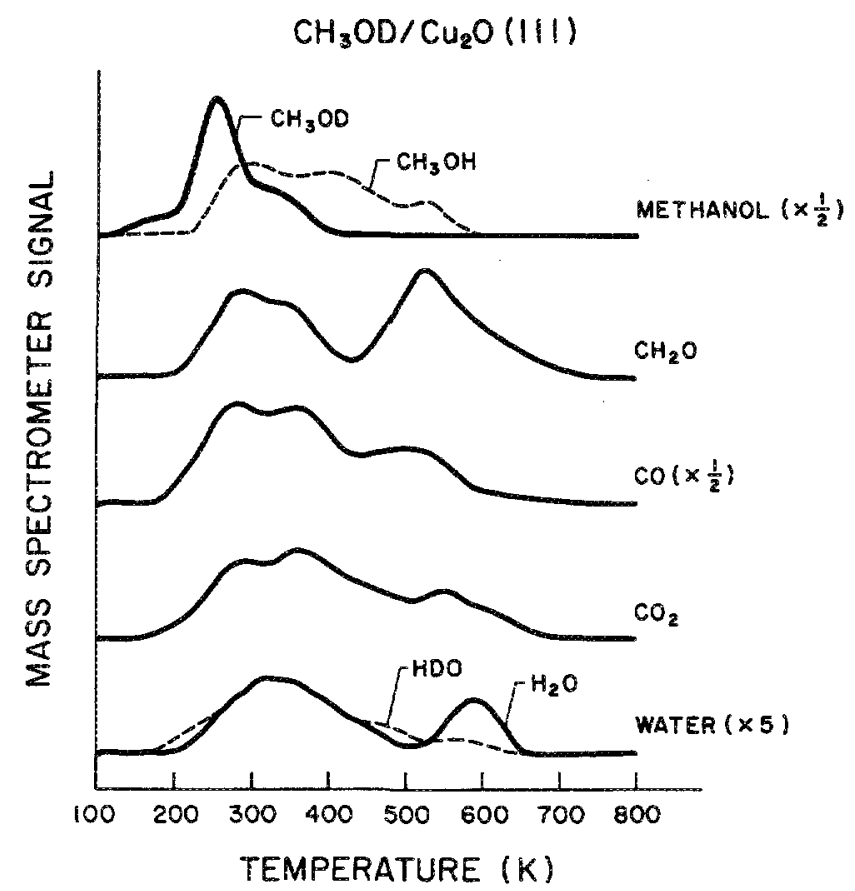

FIG. 1. Thermal desorption spectra for $\mathrm{CH}_{3} \mathrm{OD}$ decomposition on the stoichiometric $\mathrm{Cu}_{2} \mathrm{O}(111)$ surface.

While no traces are shown for dihydrogen species $\left(\mathrm{H}_{2}, \mathrm{HD}, \mathrm{D}_{2}\right)$ in Fig. 1, trace amounts of these products could be detected above the high background in the system over nearly the entire temperature range. However, very low $\mathrm{S} / \mathrm{N}$ (signal-to-noise) prevented a reasonable determination of structure in the traces. Similar problems were encountered for isotopically different forms of water. Only the most well-defined trace for HDO is reported in Fig. 1 to illustrate the temperature range over which deuterium is present on the surface. As with the dihydrogen species, low $S / N$ for the $\mathrm{D}_{2} \mathrm{O}$ signal prevented a reasonable determination of structure in the trace.

Methanol desorbed both as $\mathrm{CH}_{3} \mathrm{OD}$ and $\mathrm{CH}_{3} \mathrm{OH}$, indicating dissociation at the $\mathrm{O}-\mathrm{D}$ bond and recombination with surface hydrogen. $\mathrm{CH}_{3}$ OD desorbed primarily in two overlapping peaks centered at 255 , and $320 \mathrm{~K}$. $\mathrm{CH}_{3} \mathrm{OH}$ desorption was observed in this low temperature range, primarily in coincidence with the $320 \mathrm{~K}$ peak, however a broad desorption feature was also observed extending to higher temperatures of about $550 \mathrm{~K}$. Formaldehyde $\left(\mathrm{CH}_{2} \mathrm{O}\right)$ desorption occurred in two broad features centered at 320 and $525 \mathrm{~K}$. Similar features are also observed for $\mathrm{CO}, \mathrm{CO}_{2}$, and $\mathrm{H}_{2} \mathrm{O}$.

For the near saturation coverage associated with Fig. 1, $62 \%$ of the adsorbed methanol decomposed to oxidation products. Of the carbon containing oxidation products, $\mathrm{CO}$ was formed most selectively (52\%), and $\mathrm{CH}_{2} \mathrm{O}$ and $\mathrm{CO}_{2}$ were formed in equal amounts ( $24 \%$ each). The adsorbates leaving as molecular methanol were composed of $59 \%$ $\mathrm{CH}_{3} \mathrm{OH}$.

The peak temperature of $525 \mathrm{~K}$ for the formaldehyde desorption signal was found to be independent of coverage, 


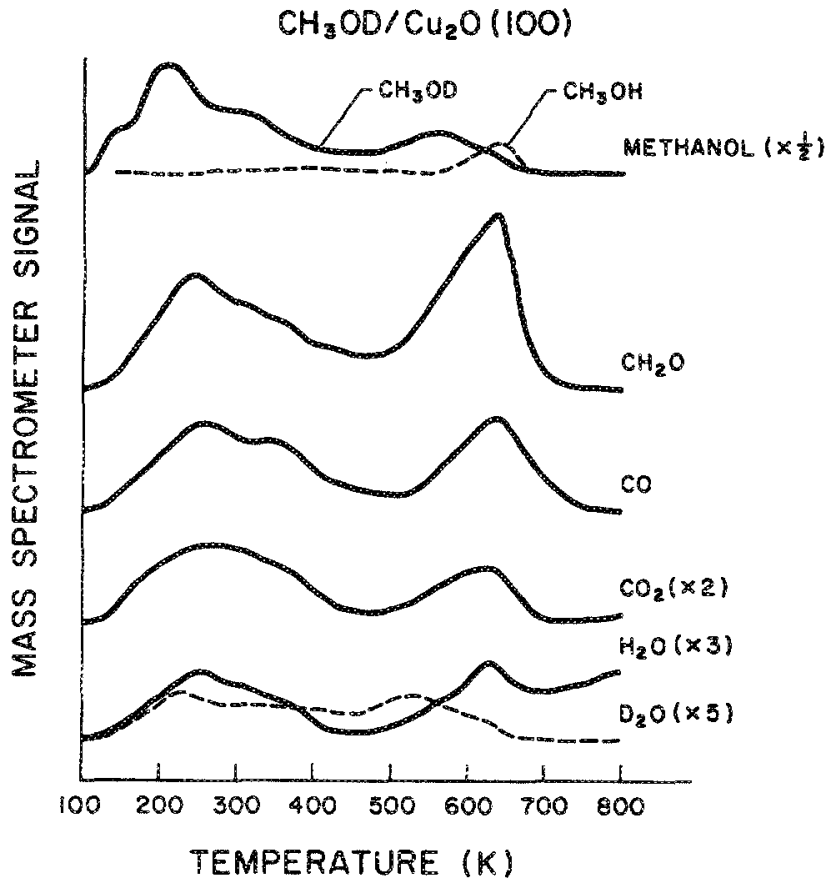

FIG. 2. TDS spectra for $\mathrm{CH}_{3} \mathrm{OD}$ decomposition on the Cu-terminated $\mathrm{Cu}_{2} \mathrm{O}(100)$ surface.

indicating a first-order decomposition reaction. Applying the Redhead equation for a first-order reaction ${ }^{22}$ and assuming a preexponential of $10^{13} \mathrm{~s}^{-1}$ gives an activation energy of $33.2 \mathrm{kcal} / \mathrm{mol}$. Because of an apparent overlap of several contributions to the low temperature formaldehyde desorption feature it is difficult to pick a maximum temperature, however there appeared to be no shifts as a function of coverage. Using an average peak temperature of $320 \mathrm{~K}$ gives a first-order activation energy of $20 \mathrm{kcal} / \mathrm{mol}$. The broadness of the descrption features for $\mathrm{CO}, \mathrm{CO}_{2}$, and $\mathrm{CH}_{3} \mathrm{OH}$ eliminated the possibility of making a reasonable determination of the order of the rate-controlling step from the TDS data.

\section{2. $\mathrm{Cu}_{z} \mathrm{O}(100)$}

The products of the reaction of $\mathrm{CH}_{3} \mathrm{OD}$ with the $\mathrm{Cu}_{2} \mathrm{O}(100)$ surface are shown in Fig. 2 for near saturation coverage. Similar products to those seer from the (111) surface were observed: $\mathrm{CO}, \mathrm{CO}_{2}, \mathrm{CH}_{2} \mathrm{O}$, and water. As with the (111) surface, no $\mathrm{CH}_{4}$, or bimolecular reaction products were observed.

For the (100) surface, trace amounts of $H D$ and $D_{2}$ were observed above the high background in the chamber, but not with sufficient $\mathrm{S} / \mathrm{N}$ to determine the true shape of the desorption traces. The only deuterated form of water reported in Fig. 2 is $\mathrm{D}_{2} \mathrm{O}$. High background and low $\mathrm{S} / \mathrm{N}$ prevented a reasonable determination of the shape of the $\mathrm{HDO}$ trace.

Methanol desorbed both as $\mathrm{CH}_{3} \mathrm{OD}$ and $\mathrm{CH}_{3} \mathrm{OH}$. $\mathrm{CH}_{3} \mathrm{OD}$ desorbed in a low-temperature feature with contributions at 215 and $320 \mathrm{~K}$, and a higher temperature feature with contributions at 560 and $630 \mathrm{~K}$. In contrast to the (111) surface, $\mathrm{CH}_{3} \mathrm{OH}$ desorption occurred only in one high temperature peak at $630 \mathrm{~K}$. Formaldehyde desorption again occurred in two features centered at about 250 and 630 $\mathrm{K}$. $\mathrm{CO}, \mathrm{CO}_{2}$, and water also desorbed in two broad peaks at temperatures similar to those for formaldehyde.

For the saturation coverage in Fig. 2, the extent of decomposition of methanol was $58 \%$, indicating a similar activity to that observed on the (111) surface. In contrast to the (111) surface, $\mathrm{CH}_{2} \mathrm{O}$ rather than $\mathrm{CO}$ was the primary oxidation product, representing $58 \%$ of the carbon containing products. The selectivity to $\mathrm{CO}$ was $34 \%$, while $\mathrm{CO}_{2}$ production accounted for only $8 \%$ of the carbonaceous oxidation products. Of the adsorbates leaving as molecular methanol, $\mathrm{CH}_{3} \mathrm{OH}$ accounted for only $9 \%$ of the total. In comparison to the (111) surface, $\mathrm{CO}_{2}$ and $\mathrm{CH}_{3} \mathrm{OH}$ production are inhibited.

The high temperature peaks ( $630 \mathrm{~K}$ ) for $\mathrm{CH}_{2} \mathrm{O}, \mathrm{CH}_{3} \mathrm{OH}$, and $\mathrm{CO}$ were found to be independent of coverage, indicating a first-order decomposition reaction. Assuming a preexponential of $10^{13} \mathrm{~s}^{-1}$ gives a first-order activation energy of $40.1 \mathrm{kcal} / \mathrm{mol}$. The low temperature formaldehyde and $\mathrm{CO}$ features appeared to be first order, although they contain several overlapping contributions. Using an average peak temperature of $250 \mathrm{~K}$ gives a first-order activation energy $\left(10^{13} \mathrm{~s}^{1}\right.$ preexponential) of $15.5 \mathrm{kcal} / \mathrm{mol}$.

\section{B. X-ray photoelectron spectroscopy}

XPS was used to characterize the surface intermediates associated with the methanol decomposition process. All spectra were collected with the sample at $90 \mathrm{~K}$. While the samples were quite conductive at room temperature, they were insulating at $90 \mathrm{~K}$, resulting in sample charging during the XPS measurements. To account for the charging, all spectra have been referenced to the $\mathrm{Cu} 2 p_{3 / 2}$ with an assigned value of $932.4 \mathrm{eV}^{23}$ The $\mathrm{Cu}$ peak shapes and FWHM's were the same as those obtained at room temperature when the samples were conductive, demonstrating that there were no problems with differential charging.

Since surface formate is often associated with $\mathrm{CO}_{2}$ desorption during methanol decomposition, an XPS investigation of the (111) surface which gives the highest $\mathrm{CO}_{2}$ yield was undertaken. Figure 3 shows the C $1 s$ XPS spectra collected following a $30 \mathrm{~L}$ dose at $90 \mathrm{~K}$ and subsequent heating to the listed temperatures with the same indirectly monitored temperature ramp used for TDS measurements. Because the crystal temperature lags behind the stage temperature during the ramp (especially at higher temperatures), the crystal temperature actually exceeds the value listed in Fig. 3 because of the time required to cool the stage after termination of the temperature ramp.

The spectrum for a $30 \mathrm{~L}$ dose gave a single symmetric peak (1.6 eV FWHM) at a binding energy of $286.8 \mathrm{eV}$, characteristic of molecular methanol in the multilayer. Heating to 155 $\mathrm{K}$ removed most of the molecular multilayer, leaving a peak still centered at $286.8 \mathrm{eV}$ but broadened to both lower and higher binding energies. Subsequent heating to $250 \mathrm{~K}$ removed any evidence of the molecular methanol peak at 286.8 $\mathrm{eV}$ and any higher binding energy contribution; a single symmetric peak with a binding energy of $285.9 \mathrm{eV}$ was left. Heating to higher temperatures caused a reduction of the peak at 


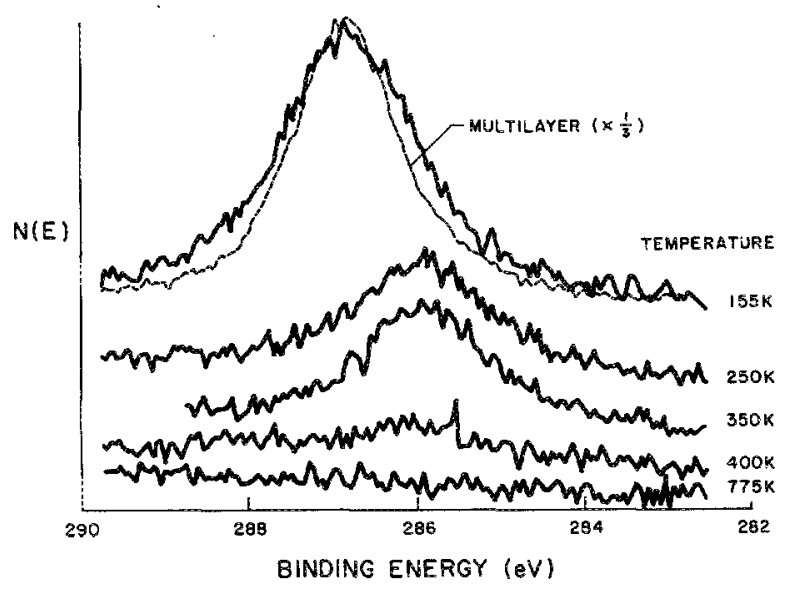

FIG. 3. C Is XPS spectra for methanol adsorbed on the $\mathrm{Cu}_{2} \mathrm{O}$ (111) surface. The signal corresponding to a methanol multilayer ( $30 \mathrm{~L}$ exposure at $90 \mathrm{~K}$ ) is shown as a dashed line and scaled to $1 / 3$ its original intensity to illustrate the broadening of the $C$ is feature following removal of the multilayer. The temperatures correspond to those of a series of consecutive heating treat ments following adsorption of the multilayer. All spectra were recorded at $90 \mathrm{~K}$.

$285.9 \mathrm{eV}$ until no carbon was left on the surface. Attempts to peak fit the broadened spectrum obtained after heating to $155 \mathrm{~K}$ suggest a feature in the binding energy range of $288.0 \pm 0.3 \mathrm{eV}$ when using the clearly observed peaks at $286.8 \mathrm{eV}$ for the main contribution and $285.9 \mathrm{eV}$ to model the low binding energy broadening.

XPS was also used as a check for changes in the surface composition and $\mathrm{Cu}$ valence states as a result of methanol exposures. The observation of $\mathrm{CO}_{2}$ desorption in TDS implies that some surface reduction must take place. However, XPS gave no indication of surface reduction resulting from the methanol exposures on the two surfaces in the TDS and XPS studies. Surface characterizations studies have shown that near-surface oxygen can act as a limited reservoir to reoxidize submonolayer deficiencies of surface lattice oxygen at temperatures near those at the end of the TDS ramp. ${ }^{24}$

\section{DISCUSSION}

\section{A. Surface intermediates}

On both the (111) and (100) surfaces methanol, formaldehyde, $\mathrm{CO}$, and $\mathrm{CO}_{2}$ production are observed in a low- and high-temperature region of the TDS traces. The simultaneous evolution of methanol, formaldehyde, and $\mathrm{CO}$ indicates that they originate from the same surface intermediate. The desorption of $\mathrm{CH}_{3} \mathrm{OH}$ clearly indicates dissociation of $\mathrm{CH}_{3} \mathrm{OD}$ at the O-D bond followed by recombination with $\mathrm{H}$ released from the methyl group. This behavior is characteristic of surface methoxy $\left(\mathrm{CH}_{3} \mathrm{O}\right.$-) dehydrogenation to formaldehyde $\left(\mathrm{CH}_{2} \mathrm{O}\right)$ and $\mathrm{CO}$, and recombination with surface hydrogen to give molecular methanol. TDS studies of $\mathrm{CO}$ on $\mathrm{Cu}_{2} \mathrm{O}$ (111) indicate that the observed CO desorption from methanol dissociation is reaction limited. ${ }^{25}$ No evidence is seen for $\mathrm{C}-\mathrm{O}$ bond breaking on either surface in the form of methane desorption or surface oxidation.
The invariance of the high-temperature desorption peaks with surface coverage indicate a first-order methoxy decomposition is rate determining. The first-order activation energies determined for the high-temperature methoxy decomposition on the two surfaces range from 33 to $40 \mathrm{kcal} / \mathrm{mol}$, and compare reasonably to the $32.4 \mathrm{kcal} / \mathrm{mol}$ reported for the $\mathrm{ZnO}(0001)-\mathrm{Zn}$ surface. ${ }^{4}$ While the low-temperature channels are not as clearly first order, the average activation energies found for the broad peaks associated with these desorption channels on the two surfaces $(15-20 \mathrm{kcal} / \mathrm{mol})$ are comparable to the value of $22.4 \mathrm{kcal} / \mathrm{mol}$ observed on Cu(110) for coadsorbed methanol and atomic oxygen. ${ }^{6}$ Thus decomposition products desorb in two temperature ranges with activation energies similar to those observed for methoxy decomposition on both $\mathrm{Cu}$ and $\mathrm{ZnO}$ surfaces. The similarity of the activation energies suggest one possible difficulty in identifying the decomposition channels associated with $\mathrm{Cu}^{+1}$ centers in the $\mathrm{Cu} / \mathrm{ZnO}$ system.

The XPS data for the (111) surface is also consistent with the formation of surface methoxy. The $0.9 \mathrm{eV}$ shift to lower binding energy (from 286.8 to $285.9 \mathrm{eV}$ ) observed for the $\mathrm{C}$ $1 s$ peak is in a direction consistent with the change observed for molecular methanol oxidation to methoxy on $\mathrm{ZnO}(0001)-\mathrm{Zn},{ }^{4}$ although the magnitude of the shift is significantly larger $(0.9 \mathrm{eV}$ compared with $0.5 \mathrm{eV})$. However, the methoxy binding energy we report is $1.1 \mathrm{eV}$ larger than the $284.8 \mathrm{eV}$ binding energy associated with hydrocarbon fragments on these $\mathrm{Cu}_{2} \mathrm{O}$ surfaces, ${ }^{25}$ again indicating no $\mathrm{C}$ $\mathrm{O}$ bond breaking of the adsorbate.

Tobin et al. ${ }^{26}$ have reported XPS observations for methanol on polycrystalline $\mathrm{Cu}_{2} \mathrm{O}$ pellets, however, they observed a decrease in the $\mathrm{C} 1 \mathrm{~s}$ binding energy of $1.4 \mathrm{eV}$ on the transition from multilayer to adsorbed species. Their investigation also included methanol adsorption on $\mathrm{ZnO}$ and $\mathrm{CuO}$, but only $\mathrm{Cu}_{2} \mathrm{O}$ caused a large decrease in the $\mathrm{C} 1$ s binding energy. They attributed the large $\mathrm{C} 1 s$ shift to an interaction between both the carbon and oxygen atoms with the surface (i.e., a molecule or intermediate oriented parallel to the surface). The shift in the $\mathrm{C} 1 s$ feature was attributed to enhanced coulombic screening of the core hole because of the proximity of the carbon atom to the surface [i.e., an extramolecular relaxation polarization (ERPS) shift].

The possibility of a large ERPS shift for methoxy carbon on $\mathrm{Cu}_{2} \mathrm{O}(111)$ is also reasonable because of the open structure of the cuprite lattice, although it does not necessarily indicate a parallel surface intermediate. On the (111) surface we note that there is sufficient room for vertically oriented methoxy to bond to a second layer, singly coordinated Cu cation with the carbon atom of the methyl group close to the top layer of oxygen anions. ERPS effects associated with the open structure of the surface may account for our low $\mathrm{C}$ $1 s$ binding energy for surface methoxy compared to $\mathrm{ZnO}$. A brief discussion of the $\mathrm{Cu}_{2} \mathrm{O}$ surface structures is given in Sec. IV B.

On the basis of their XPS data and the observation of $\mathrm{Cu}_{2}\left(\mathrm{OCH}_{3}\right)$ and $\mathrm{Cu}_{3}\left(\mathrm{CH}_{2}\right)$ by SIMS of adsorbed methanol, Tobin et al ${ }^{26}$ conclude that methoxy is formed with some $\mathrm{C}-\mathrm{O}$ bond breaking on polycrystalline $\mathrm{Cu}_{2} \mathrm{O}$. While we see no evidence for $\mathrm{C}-\mathrm{O}$ bond breaking in TDS or in our 
XPS measurements for $\mathrm{Cu}_{2} \mathrm{O}(111)$, we note that the $\mathrm{C}$ is binding energy of $284.8 \mathrm{eV}$ reported by Tobin et al. ${ }^{26}$ for adsorbed methanol at $300 \mathrm{~K}$ is identical to the value seen on our single crystals for hydrocarbon fragments. ${ }^{25}$ Because of the structure sensitivity of the product distribution from TDS on $\mathrm{Ca}_{2} \mathrm{O}(100)$ and (111), it may be possible that different crystallographic surfaces on their polycrystalline materials were responsible for $\mathrm{C}-\mathrm{O}$ bond breaking.

$\mathrm{CO}_{2}$ desorption is often associated with surface carboxylate decomposition. ${ }^{2,4,6,18,27} \mathrm{AC}$ is feature at a higher binding energy than that exhibited by molecular methanol should be observed in the event of a detectable concentration of surface formate. Our XPS results in Fig. 3 show only marginal evidence (broadening to higher binding energies) for a stable surface intermediate leading to $\mathrm{CO}_{2}$ production on the $\mathrm{Cu}_{2} \mathrm{O}(111)$ surface. The high binding energy contribution is observed following desorption of the multilayer, and is completely removed in a temperature range near that observed for the maximum desorption rate of $\mathrm{CO}_{2}$. This XPS contribution near $288 \mathrm{eV}$ is consistent with surface formate. Methoxy oxidation to formate has been observed via XPS on $\mathrm{ZnO}(0001)-\mathrm{Zn}$ with an increase in binding energy of $2.5 \mathrm{eV}$ above that of methoxy, ${ }^{4}$ in comparison to our observed increase of $2.1 \pm 0.3 \mathrm{eV}$. Surface methoxy and formate have been observed on oxidized copper in the presence of methanol vapor by double-modulation Fourier-transform infrared spectroscopy (FTIR). ${ }^{28}$

Extensive investigations of the chemistry of the $\mathrm{ZnO}(0001)-\mathrm{Zn}$ face show a general trend of this surface for nucleophilic attack of lattice oxygen on hydrocarbons to form surface carboxylates. ${ }^{29}$ The low selectivity to $\mathrm{CO}_{2}$ on $\mathrm{Cu}_{2} \mathrm{O}$ compared to that observed on $\mathrm{ZnO}(0001)-\mathrm{Zn}$ suggests formate species are either unstable on our $\mathrm{Cu}_{2} \mathrm{O}$ surfaces, or have higher activation energies for formation from surface methoxy than do the desorption pathways of the dehydrogenation products. Formic acid TDS studies are planned to investigate the stability and decomposition pathways of surface formate.

\section{B. Structure sensitivity}

The structure sensitivity of the reaction of methanol on $\mathrm{Cu}_{2} \mathrm{O}(111)$ and (100) surfaces is demonstrated clearly by the differences in product yield in the TDS experiments for a saturated surface. $\mathrm{CO}$ is the most abundant product from the (111) surface ( $52 \%$ selectivity) while $\mathrm{CH}_{2} \mathrm{O}$ is the most abundant product from the (100) surface ( $58 \%$ selectivity). Since the conversions on the two surfaces were both about $60 \%$, the changes in selectivity represent true changes in the yield of the two products. Thus, the (111) surface tends towards complete dehydrogenation of surface methoxy, while the (100) surface is more selective to partial dehydrogenation. The lower activity for complete dehydrogenation on the (100) surface is also accompanied by a decreased activity for oxidation to $\mathrm{CO}_{2}$.

A comparison of the activation energy for methoxy decomposition on the two surfaces can be related to the change in dehydrogenation activity. Using the high temperature formaldehyde peaks where the desorption in clearly first order, we find an increase in activation energy for methoxy decom. (a)

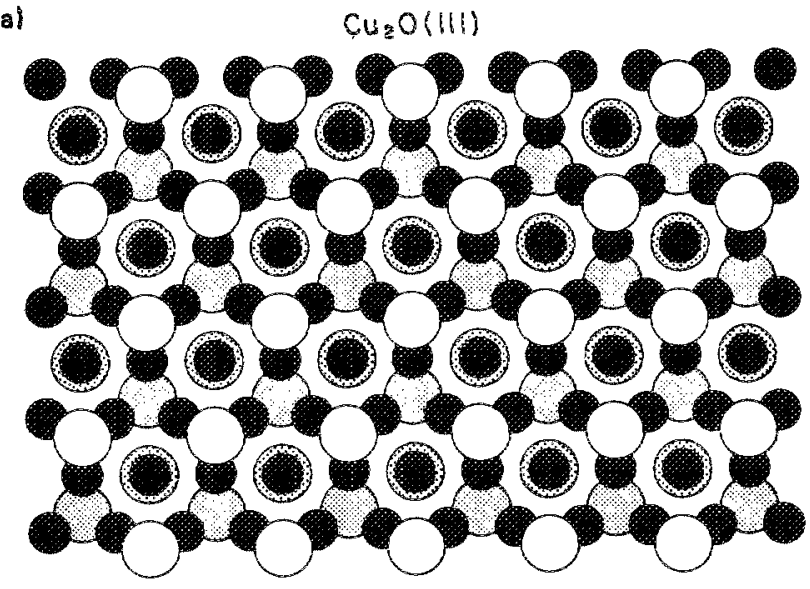

(b)

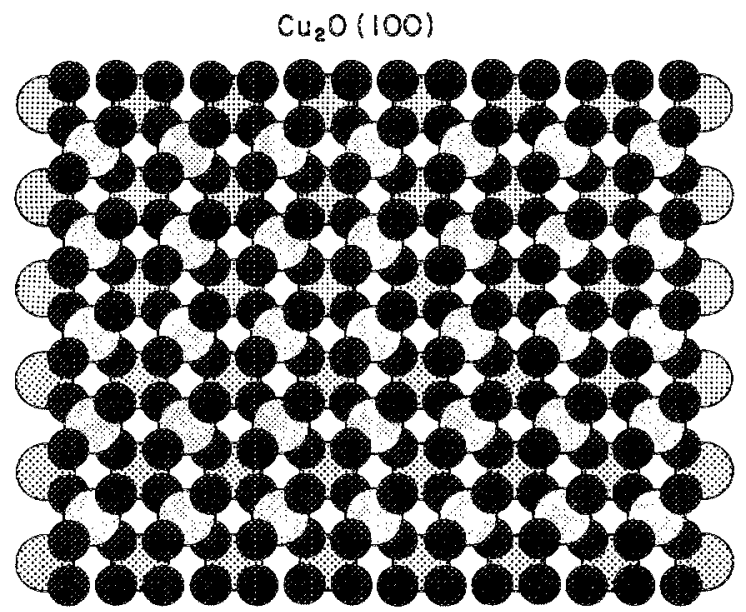

FIG. 4. Ball model illustations of the (a) stoichiometric, nonpolar $\mathrm{Cu}_{2} \mathrm{O}(111)$ surface, and the (b) unreconstructed, polar, $\mathrm{Cu}$-terminated $\mathrm{Cu}_{2} \mathrm{O}(100)$ surface. The small dark circles represent $\mathrm{Cu}+$ ' cations and the larger open circles represent $\mathrm{O}^{2}$ anions. Increased shading of the oxygen anions represents increasing distance away from the surface. For clarity, only the top four atomic layers are shown of each surface.

position of about $7 \mathrm{kcal} / \mathrm{mol}$ for the (100) surface. A similar difference in activation energies has also been observed for allyloxy decomposition on these surfaces. ${ }^{25}$

$\mathrm{Cu}_{2} \mathrm{O}$ crystallizes in the cuprite structure $(\mathrm{Pn} 3)$ which is unusual because the cations are only twofold-coordinate, and form linear $\mathrm{O}-\mathrm{Cu}-\mathrm{O}$ linkages. ${ }^{30}$ The unusual structure gives rise to open surfaces in which second and third layer atoms are accessible at the surfaces. Ball model illustrations of the $\mathrm{Cu}_{2} \mathrm{O}(111)$ and unreconstructed $\mathrm{Cu}_{2} \mathrm{O}(100)$ surfaces are shown in Fig. 4. Figure 4(a) represents a stoichiometric (111) surface which exposes singly and doubly coordinated $\mathrm{Cu}$ cations in the second atomic layer. Previous work has shown that this stoichiometric surface may be prepared by ion bombardment and annealing in vacuum, presumably because there is no preferential removal of oxygen by ion bombardment. ${ }^{24,31}$ Figure $4(\mathrm{~b})$ illustrates the unreconstructed, $\mathrm{Cu}$ terminated (100) surface which has a square periodicity. This figure is a highly idealizeo illustration of the actual (100) surface which reconstructs to give a 
$(3 \sqrt{2} \times \sqrt{2}) R 45^{\circ}$ LEED pattern with many missing spots. The observed periodicity can be described best as an oblique lattice. The reconstruction can be lifted in the presence of weakly adsorbed atomic oxygen to give a square $(1 \times 1)$ LEED pattern, suggesting that the reconstruction is due to a relaxation between neighboring copper cations, rather than a gross restructuring of the surface. ${ }^{24}$ XPS, UPS, LEED and adsorption studies demonstrate that the (100) surface prepared by ion bombardment and annealing is copper terminated and exposes a high concentration of singly coordinated cations, like the idealization in Fig. 4(b). ${ }^{24}$

A comparison of the composition and structure of the two surfaces suggests that the higher dehydrogenation activity of the (111) surface is related to the outer atomic layer of oxygen anions at the surface. All the exposed $\mathrm{Cu}$ cations at the (111) surface are in the second atomic layer. A surface methoxy bound at either singiy or doubly coordinated $\mathrm{Cu}$ cation sites has coordinately unsaturated oxygen anions in close proximity. These oxygen anions may act as hydrogen abstraction sites for the dehydrogenation of methoxy and as an oxygen source for the formation of $\mathrm{CO}_{2}$, possibly through a surface formate intermediate.

In contrast to the (111) surface, the (100) surface presents a terminating layer of Cu cations with oxygen anions in the second atomic layer. The idealized picture in Fig. 4(b) shows that second layer anions should be accessible for methanol decomposition, but would be a considerable distance from the methyl group of a surface methoxy oriented perpendicular to the surface on a top-layer cation site. The spatial separation could account for the increased activation energy for methoxy decomposition at high temperature on this surface.

We note that these observations about the structure and chemistry of the two $\mathrm{Cu}_{2} \mathrm{O}$ surfaces do not explain all the observed details of the surface chemistry. For example, the $\mathrm{ZnO}(0001)-\mathrm{Zn}$ surface predominantly oxidizes methoxy to formate via nucleophilic attack of lattice oxygen atoms despite their second layer location. ${ }^{2,4}$ Also, our explanation of the increased activation energy for methoxy decomposition with the decrease in surface oxygen does not account for the low-temperature decomposition pathway observed over $\mathrm{Cu}_{2} \mathrm{O}(100)$. Vibrational spectroscopy would be useful for investigating the variety of possible methoxy adsorption sites and the interaction of the reaction intermediates with neighboring surface anions and cations.

\section{ACKNOWLEDGMENTS}

We gratefully acknowledge the Donors of The Petroleum Research Fund, administered by the American Chemical
Society, for the support of this research. We also thank Professor $\mathrm{L}$. Tapiero for providing the single crystals used in this study.

a) To whom correspondence should be addressed.

'J. P. Lu, M. Albert, S. L. Bernasek, and D. S. Dwyer, Surf. Sci. 218, 1 (1989), and references therein.

${ }^{2}$ S. Akhter, W. H. Cheng, K. Lui, and H. H. Kung, J. Catal. 85, 437 (1984).

${ }^{3}$ W. Hirschwald and D. Hofmann, Surf. Sci. 140, 415 (1984)

${ }^{4}$ J. M. Vohs and M. A. Barteau, Surf. Sci. 176, 91 (1986).

${ }^{5}$ J. M. Vohs and M. A. Barteau, Surf. Sci. 197, 109 (1988).

${ }^{6}$ I. E. Wachs and R. J. Madix, J. Catal. 53, 208 (1978).

${ }^{7}$ M. Bowker and R. J. Madix, Surf. Sci. 95, 190 (1980).

${ }^{8}$ K. Klier, Adv. Catal. 31, 243 (1982).

${ }^{9}$ G. A. Vedage, R. Pitchai, R. G. Herman and K. Klier, Proceedings of the 8th International Congress on Catalysis, West Berlin (unpublished), Vol. 2. p. 47.

${ }^{10}$ G. A. Vedage, R. G. Herman, and K. Klier, J. Catal. 95, 423 (1985).

"G. C. Chinchen, P. J. Denny, D. G. Parker, G. D. Short, M. S. Spencer, K. C. Waugh, and D. A. Whan, Reprints of the Division of Fuel Chemistry, ACS 29, 178 (1984).

${ }^{12}$ G. C. Chinchen, K. C. Waugh, and D. A. Whan, Appl. Catal. 25, 101 (1986).

${ }^{13}$ K. Shimomura, K. Ogawa, M. Oba and Y. Dotera, J. Catal. 52, 191 (1978).

${ }^{14}$ J. C. Frost, Nature 334, 577 (1988).

${ }^{5}$ K. Klier, Appl. Surf. Sci. 19, 267 (1984).

${ }^{16}$ R. G. Herman, K. Klier, G. W. Simmons, B. P. Finn, J. B. Bulko, and T. P. Kolylinski, J. Catal. 56, 407 (1979).

"S. Mehta, G. W. Simmons, K. K.lier and R. G. Herman, J. Catal. 57, 339 (1979).

${ }^{18}$ L. Chan and G. L. Griftin, Surf. Sci. 173, 160 (1986).

${ }^{19}$ C. T. Campbell, K. A. Daube, and J. M. White, Surf. Sci. 182, 458 (1987).

${ }^{20}$ J. L. Loison, M. Robino and C. Schwab, J. Crystal Growth 50, 816 (1980).

${ }^{21}$ R. Ryberg, Phys. Rev. Lett. 49, 1579 (1982).

${ }^{22}$ P. A. Redhead, Vacuum 12, 203 (1962).

${ }^{23}$ G. E. Muhlenberg, Handbook of X-Ray Photoelectron Spectroscopy (Perkin-Elmer, Eden Prairie, MN, 1978).

${ }^{24}$ K. H. Schulz and D. F. Cox (in preparation).

${ }^{25}$ K. H. Schulz and D. F. Cox (work in progress).

${ }^{26} \mathrm{~J}$. Tobin, W. Hirschwald, and J. Cunningham, Spectrochim. Acta Part B 40, 725 (1985).

${ }^{27}$ I. E. Wachs and R. J. Madix, Surf. Sci. 84, 375 (1979).

${ }^{28}$ Y. Sakata, K. Domen, K. Maruya and T. Onishi, Appl. Surf. Sci. 35, 363 $(1988-89)$.

2\%J. M. Vohs, Ph.D. thesis, University of Delaware, 1988.

${ }^{30}$ A. F. Wells, Structural Inorganic Chemistry, 4th ed. (Clarendon, Oxford, 1975), p. 935

${ }^{31}$ J. Herion, G. Scharl, and M. Tapiero, Appl. Surf. Sci. 14, 233 (1982-83). 